\title{
An influence of impact energy on magnesium alloy behaviour
}

\author{
Tadeusz Szymczak (i) - Katarzyna Makowska • Zbigniew L. Kowalewski • \\ Piotr Lasota
}

Received: 4 February 2019/Accepted: 11 May 2019/Published online: 23 May 2019

(C) The Author(s) 2019

\begin{abstract}
The paper reports experimental results describing behaviour of the AM60 magnesium alloy under impact test. The material was examined at energy in the range from 170 to $690 \mathrm{~J}$, using impact tower with the projectile of conical shape. Results are presented in a form of variations of accumulated energy, force, projectile velocity and its displacement versus time. The characteristic features appearing in courses of force and accumulated energy are illustrated. Fractography and microstructure of damage zones for distinguishing the alloy degradation are shown. The fracture regions of the material examined are represented by cracks and plug-shaped deformation.
\end{abstract}

T. Szymczak ( $₫) \cdot$ K. Makowska .

Z. L. Kowalewski · P. Lasota

Centre for Material Testing, Motor Transport Institute, ul. Jagiellonska 80, 03-301 Warsaw, Poland

e-mail: tadeusz.szymczak@its.waw.pl

K. Makowska

e-mail: katarzyna.makowska@its.waw.pl

Z. L. Kowalewski

e-mail: zkowalew@ippt.pan.pl

P. Lasota

e-mail: piotr.lasota@its.waw.pl

\section{Z. L. Kowalewski}

Department of Experimental Mechanics, Institute of Fundamental Technological Research, ul. Pawinskiego

5B, 02-106 Warsaw, Poland
Keywords Magnesium alloy · Impact · Projectile · Perforation · Fractography $\cdot$ Microstructure

\section{Introduction}

The magnesium alloys with respect of the specific low-value weight of $1.8 \mathrm{~g} / \mathrm{cm}^{3}$ are becoming more and more popular materials, even in comparison to aluminium alloys (Musfirah and Jaharah 2011). Their impact strength and stress-strain curve more suitably answer contemporary requirements. The first mentioned parameter increases at temperature from -50 to $150{ }^{\circ} \mathrm{C}$ (Hebben 2010) while the stress-strain curves are almost insensitive to the tensile velocity within a range of 1-300 $\mathrm{mm} / \mathrm{min}$, (Yan et al. 2008). Impact resistance of the alloy (AM60) is strongly related to manufacturing processes applied during production. Its difference can reach even 30\% (DiCecco et al. 2012). This alloy can be used for production of the composite containing various reinforcements (Zhang et al. 2015). Addition of the $\mathrm{Al}_{2} \mathrm{O}_{3}$ fibres may influence such mechanical parameters of the material like elongation and ultimate tensile strength for example. It has to be emphasized that mechanical behaviour of the magnesium alloy strongly depends on its structure. It can be observed by comparison of the tensile curve for MgAl6Mn to the characteristics of other magnesium alloys like $\mathrm{MgAl}_{2} \mathrm{Si}$ or $\mathrm{MgAl}_{5} \mathrm{Mn}$. Significant difference between 
the yield point and ultimate tensile strength can be easily noticed (Hebben 2010). It is worth mentioning that all depicted here mechanical features of magnesium alloys do not present their complex properties. Therefore, in order to broaden knowledge on the material's behaviour another test types are employed. A relatively serious interest has been focused on the perforation testing where an impact between nondeformable projectiles and metallic or composite plates are analysed (Ambrosini 2015; Dey et al. 2007; Godzimirski et al. 2015; Moćko and Kowalewski 2013; Tomac et al. 2008; Zhong et al. 2016). Such tests are usually designed using special facilities (Borvik et al. 2002a, b, 2003; Cheshire et al. 2008; Gupta et al. 2006, 2007). During such kind of impact loading, petalling appears as a failure mode when hemispherical or conical projectiles are applied (Wierzbicki 1999). It has been found that failure mode depends strongly on the impact velocity (Rusinek et al. 2009). Petalling can be replaced by failure mode of crack opening when impact velocity is close to the ballistic limit. Hence, a decrease of the circumferential strain slows the crack propagation (Shen et al. 2002). If the impact velocity is very high, the perforation process is controlled by inertia effect and as a consequence, the failure mode changes from petalling to complete fragmentation of the zone located close to place of impact, enforcing appearance of debris cloud (Piekutowski 1999). At relatively low impact velocity no external cracks appeared in the specimen impacted (Rusinek et al. 2009), and just this case will be taken into account in the paper.

In many testing stands an examination plate is the main element of a target (Ambrosini 2015; Godzimirski et al. 2015; Zhong et al. 2016). Usually, a puncher has a shape of the typical projectile (Ambrosini 2015; Dey et al. 2007; Zhong et al. 2016) or a ball (Godzimirski et al. 2015). A special lighting system and high speed camera are used for the online capturing of material degradation process during impact. Another, more complex solution, is presented by Zhong et al. (2016). The authors have proposed application of the multi-plate gripping system with force sensors in region of the specimen location.

Results of the perforation test are usually provided in a form of variations of penetration depth versus projectile velocity (Ambrosini 2015). An impact of angle variations between the projectile trajectory and plate orientation is comprehensively tested. Perforation tests are also designed to identify deformation stages of both a plate and projectile by means of the high speed camera (Dey et al. 2007). The relationship between the initial velocity and its residual value is presented for different values of the plate thickness. Deformation of specimen is analysed to distinguish some features in radial direction. Similar experimental approach was applied during perforation test carried out by Ambrosini (2015). Additional features of materials tested are presented on the basis of analysis of projectile velocity and penetration depth variation versus time. Material behaviour is also interpreted applying relationships between initial and residual projectile velocity, energy dissipation and images of deformed regions (Zhong et al. 2016).

In a limited number of laboratories the impact resistance of materials is evaluated with the use of the impact tower, (INSTRON). This type of device is usually controlled by computer and dedicated software. The results are often expressed by variations of the accumulated energy, projectile velocity, force, and specimen deflection versus time. The main advantage of the impact tower is the possibility to apply different shapes of projectiles and specimens.

Although contemporary equipment for impact tests is widespread in many laboratories and used to test different materials, only limited number of available results concern magnesium alloys. Therefore, this paper is dedicated to supplement this gap by determining the impact resistance of the magnesium alloy (AM60) under a wide range of energy levels applying multi-sensors impact tower for capturing digital results as a function of time. This aim was reached by careful analysis of the following parameters: accumulated energy, force, velocity and displacement of projectile together with the fracture regions and material microstructure. Such results enable to evaluate the alloy behaviour as a function of time at the wide range of accumulated energy, and more importantly, create database for the numerical modelling. The last mentioned topic will be presented in the accompanying paper being in preparation at the moment. 


\section{Experimental procedure}

The AM60 magnesium alloy was examined under four levels of impact energy: 170, 260, 540 and $690 \mathrm{~J}$. The mass of the dropped weight with the projectile was constant and equal to $5.77 \mathrm{~kg}$. The impact energy was set by selection of the required distance between the specimen and projectile. Specimens were disc-shaped, of $10 \mathrm{~mm}$ thick (Fig. 1). Each specimen was mounted in a special gripping system of metallic plates with a hole enabling free movement of the projectile, Figs. 2 and 3. Two screws positioned the specimen's centre in the major axis of the projectile. A radius and angle of the projectile tip were $2 \mathrm{~mm}$ and $30^{\circ}$, respectively, Fig. 3.

All tests were carried out at room temperature using the 9250 HV Dynatup Instron impact tower, Fig. 4. The impact energy capacity for the station is within the range 9-900 J. Sensors of the Instron Dynatup enabled measurement of variations of accumulated energy, force, and projectile velocity versus time.

Microstructural observations were performed with the use of the Olympus PMG3 light microscope and JEOL 6360LA scanning electron microscope. Specimens of the magnesium alloy for microstructural observation were etched with a chemical reagent of the following composition: $70 \mathrm{ml}$ of ethanol, $10 \mathrm{ml}$ of distilled water, $10 \mathrm{ml}$ of acetic acid and $4.2 \mathrm{~g}$ of picric acid.

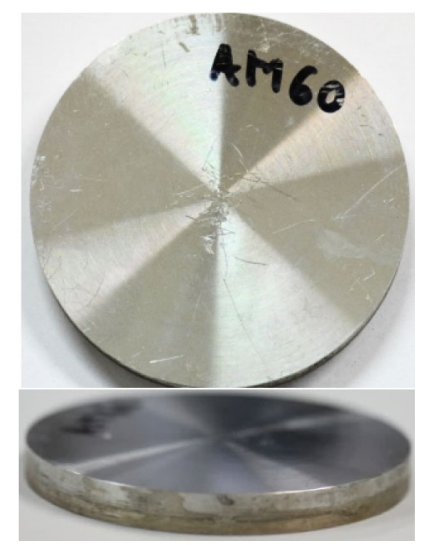

Fig. 1 Specimen made of the AM60 magnesium alloy before test, dimensions: $\phi 95 \times 10[\mathrm{~mm}]$

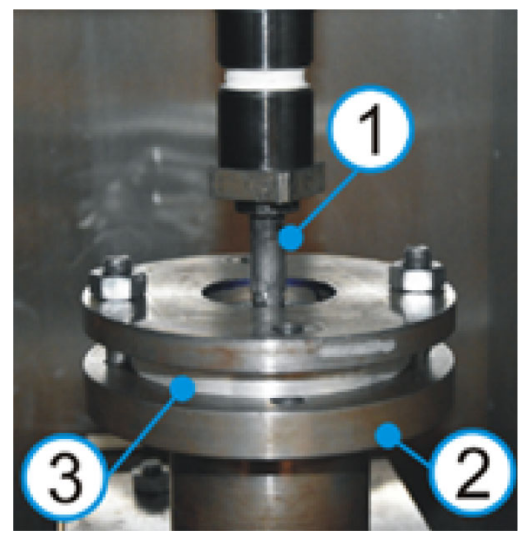

Fig. 2 Specimen mounted in the testing part of the 9250HV Dynatup Instron impact tower: 1-projectile, 2-mounting system, 3-specimen

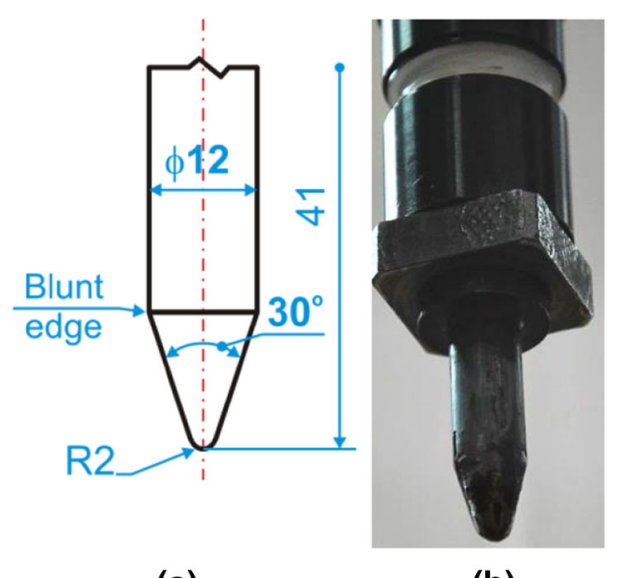

(a)

(b)

Fig. 3 The projectile: a shape and dimensions; b mounted in the drop tower

\section{Experimental results}

\subsection{Material characterisation}

Before execution the main experimental program the material in question was subjected to chemical composition analysis, hardness testing and uniaxial tensile test. The results of chemical composition inspection are summarized in Table 1, while the data representing material hardness using Brinell's scale in Table 2. In Fig. 5 the tensile curve of the AM60 alloy is presented. All necessary mechanical parameters determined from the tensile test are specified in this 


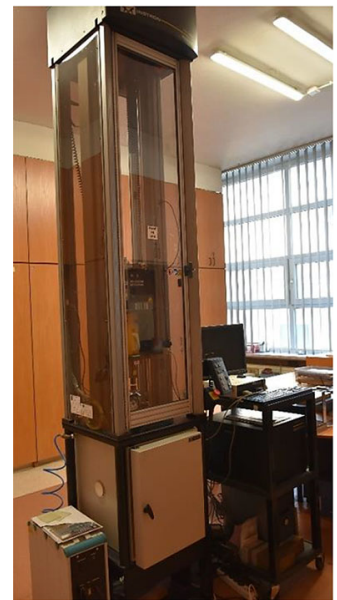

(a)

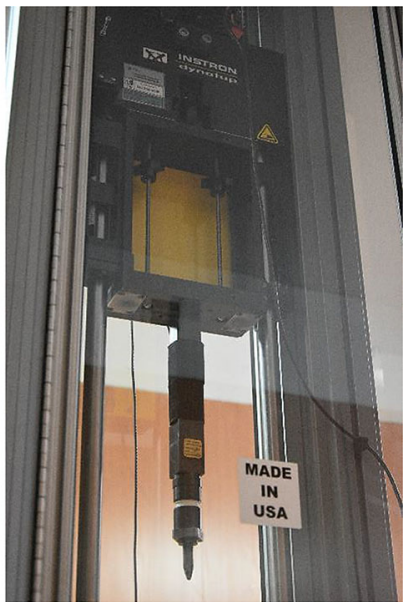

(b)
Fig. 4 The 9250HV Dynatup Instron impact tower before examination of the AM60 alloy: a the main testing column, $\mathbf{b}$ the box for weight with dynamometer and the projectile

figure. One can notice a non-linear hardening character of this material up to the fracture.

\subsection{The results of impact tests}

Experimental data obtained at impact energy within a range of 170-690 J are presented in Figs. 6, 7, 8, 9 and 10 , showing variations of accumulated energy, force, and projectile velocity as a function of time. For the smallest impact energy level accumulated energy reached $170 \mathrm{~J}$ and with respect to the penetration depth its variation may be well described by the linear function (Fig. 6a).

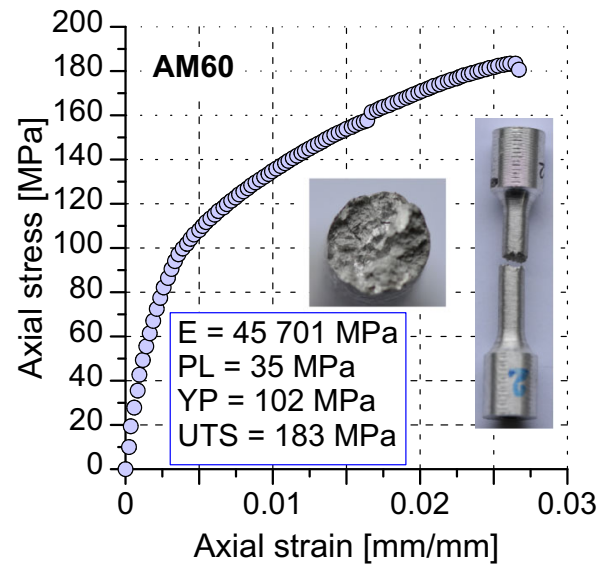

Fig. 5 Tensile curve of the AM60 alloy: $E$ Young's modulus, $P L$ proportional limit, $Y P$ yield point, UTS ultimate tensile strength

A force curve showed two local maxima of the same values and a local minimum, expressing variations of material response to penetration, i.e. hardening and softening as an effect of the projectile impact, Fig. 6a. This is also reflected by differences in the alloy fracture, i.e. changes from plastic to brittle. Similar curves of velocity and force were observed at energy of $260 \mathrm{~J}$, but in this case differences in the material fracturing were more visible, Fig. 6b. Opposite to the force value at final stage for both levels of impact energy the projectile velocity was totally reduced up to zero value. This was demonstrated by not entire perforation through the thickness of the specimen subjected to impact energy of $170 \mathrm{~J}$, Fig. 6 a. In the case of test under $260 \mathrm{~J}$, the projectile

Table 1 Chemical composition of the AM60 alloy

\begin{tabular}{lllllllllll}
\hline $\mathrm{Mn}(\%)$ & $\mathrm{P}(\%)$ & $\mathrm{Si}(\%)$ & $\mathrm{Ni}(\%)$ & $\mathrm{Fe}(\%)$ & $\mathrm{Ca}(\%)$ & $\mathrm{Al}(\%)$ & $\mathrm{Zn}(\%)$ & $\mathrm{Th}(\%)$ & $\mathrm{Be}(\%)$ & $\mathrm{Mg}(\%)$ \\
\hline 0.31 & 0.004 & 0.022 & 0.002 & 0.012 & 0.0005 & 6.14 & 0.3 & 0.06 & 0.001 & 93.4 \\
\hline
\end{tabular}

Table 2 The results of Brinell's hardness test on the AM60 alloy

\begin{tabular}{lll}
\hline Specimen number & Hardness method & Hardness for the specimen (MPa) \\
\hline No. 1 & HBW5/250 & 56.4 \\
No. 2 & HBW5/250 & 58.9 \\
No. 3 & HBW5/250 & 56.4 \\
Average value of the hardness & & 57.2 \\
\hline
\end{tabular}


(a)

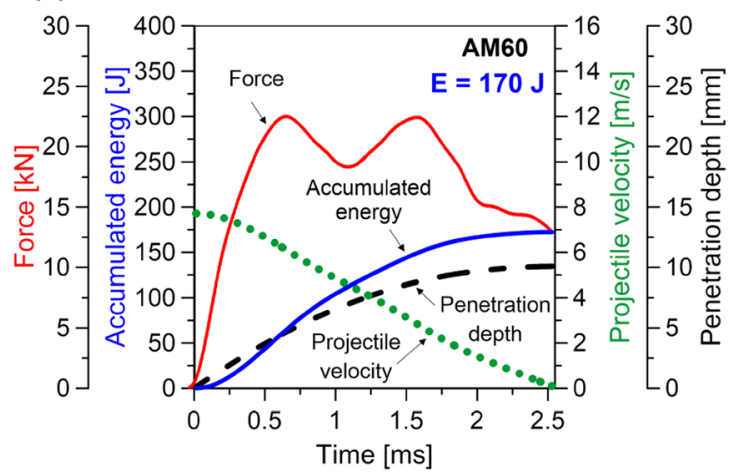

(b)

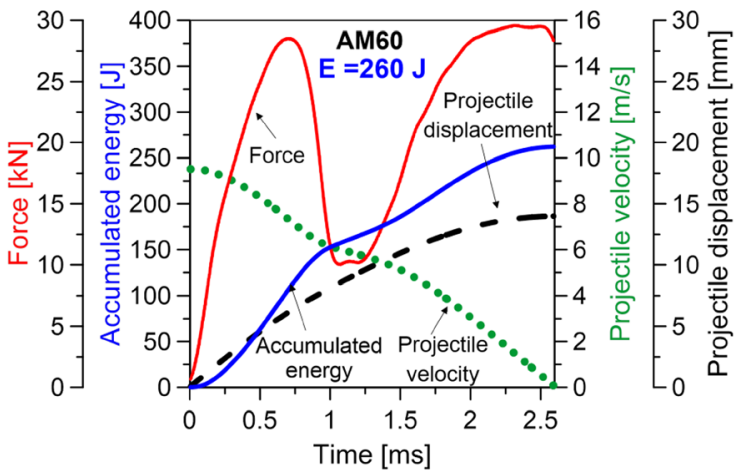

Fig. 6 Force, accumulated energy, projectile velocity, penetration depth (a) and projectile displacement (b) versus time for two levels of impact energy: $170 \mathrm{~J} ; 260 \mathrm{~J}$, respectively

(a)

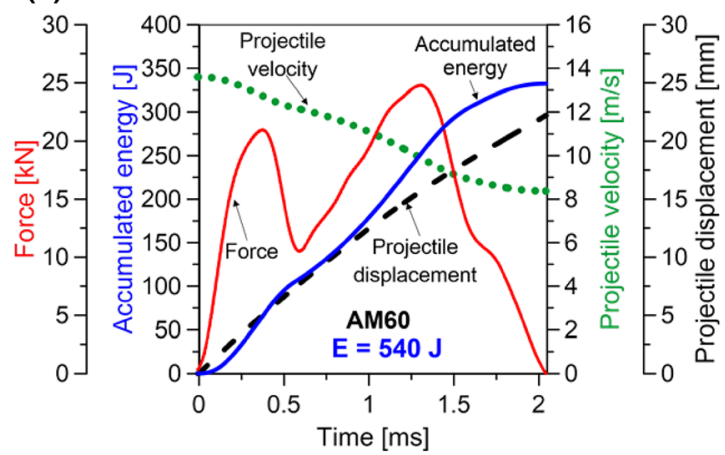

(b)

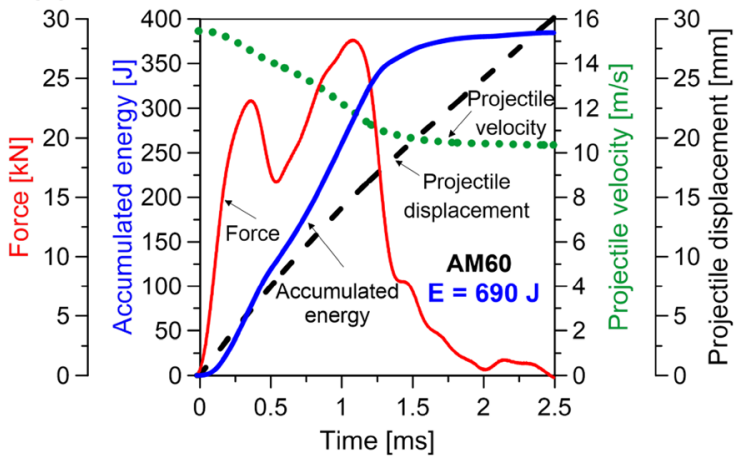

Fig. 7 Force, accumulated energy, projectile velocity and projectile displacement versus time for two levels of impact energy: a $540 \mathrm{~J}$; b $690 \mathrm{~J}$

(a)

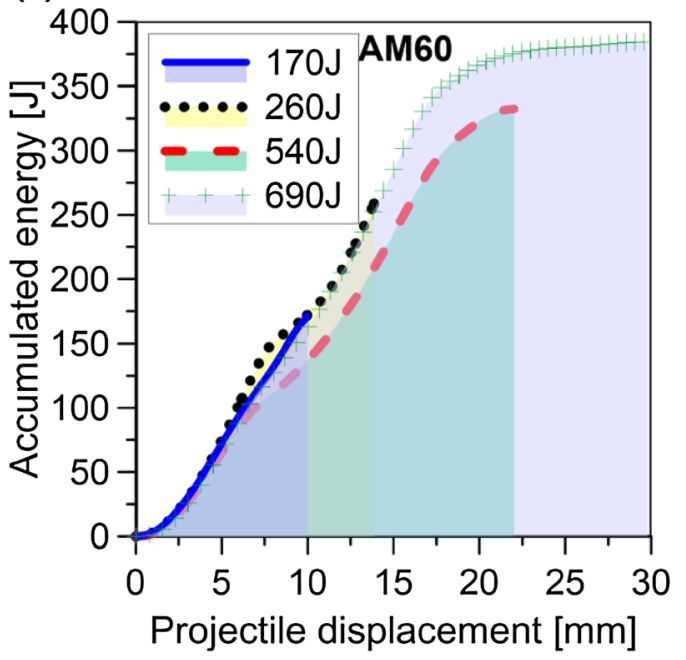

(b)

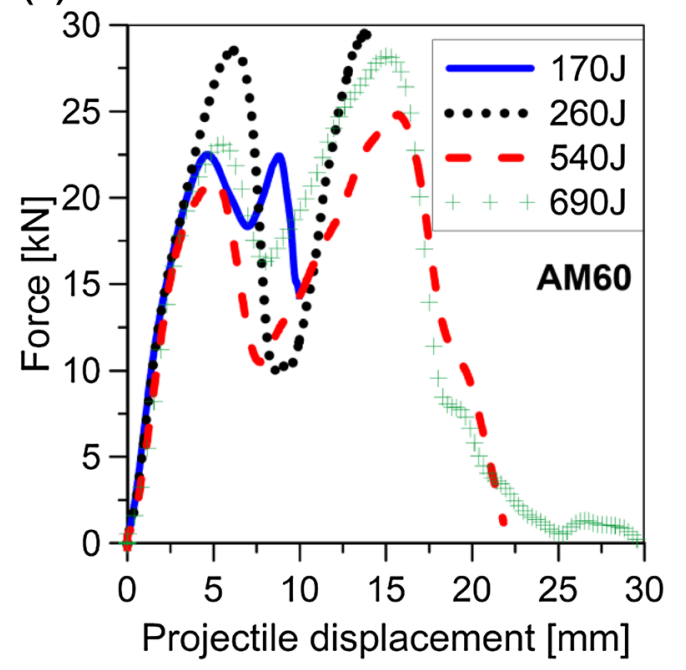

Fig. 8 Variations of: a accumulated energy, $\mathbf{b}$ force versus projectile displacement 


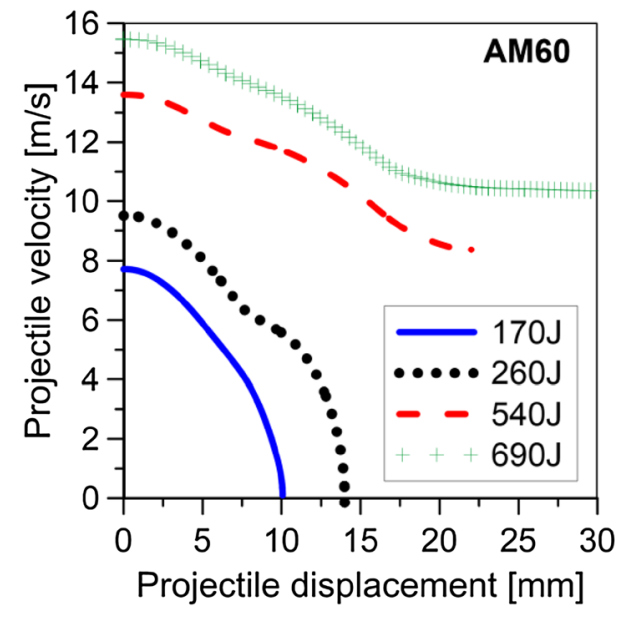

Fig. 9 Projectile velocity as a function of projectile displacement

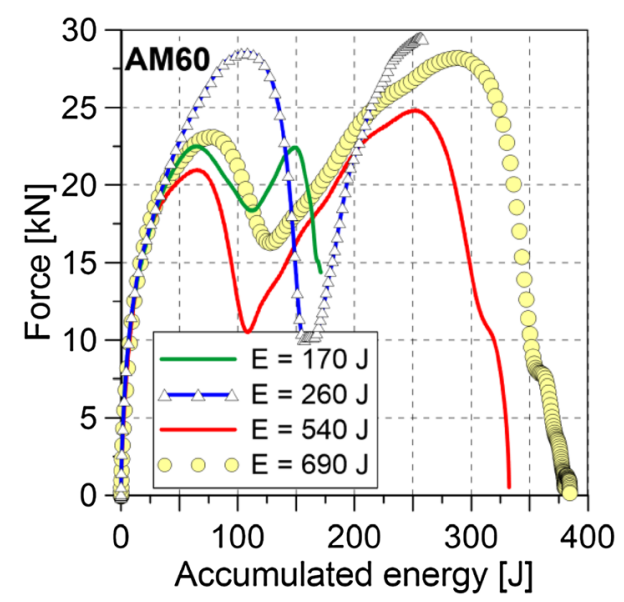

Fig. 10 Force versus accumulated energy

displacement exceed the specimen's thickness, but the hole as an effect of the impact test was not observed. This is related to a movement of the material in a form of the deformed plug behind the specimen thickness. It was captured by fractography observations, Fig. 13. Some differences related to energy values considered were observed for the accumulated energy curves, Fig. 6.

The results achieved at $540 \mathrm{~J}$ (Fig. 7a) and $690 \mathrm{~J}$ (Fig. 7b) exhibit clear changes in comparison to the results obtained for the lower values of impact energy. Although in the force variation one can find two local maxima as before, they do not reach the same level. The second one is significantly higher, expressing the alloy hardening in the course of projectile action. In the case of projectile velocity variation a gradual decrease is observed, however, it did not achieve zero level like in the case of tests under lower values of impact energy. It can be explained by analysis of variations of force and velocity at the final stage of penetration, indicating vanishing material resistance on impact due to occurrence of a hole, Figs. 15 and 16. A comparison of accumulated energy curves obtained for the four levels of impact energy exhibits significant differences, especially for the highest impact energy applied. In the final stage of projectile displacement it tends to a constant value, Fig. 8a. In Fig. 8 b force variations are presented for all tested impact energy levels. In each case two maxima are observed. For the lower impact energy they are of almost identical value. For higher levels of impact energy the second maximum has significantly greater value. This shows hardening of the tested material as an effect of the energy level applied. In comparison to the specimen's thickness, the lowest values of the force occurred at the projectile displacement of 7-9 mm, i.e. in a final stage of alloy degradation. The similar trend can be observed in Fig. 10 illustrating variation of force as a function of the accumulated energy. An analysis of the force variations indicates the accumulated energy range for the effect occurrence. This is determined by the values from 100 up to $170 \mathrm{~J}$.

The projectile velocity variations are also illustrated as a function of the projectile displacement, Fig. 9. It shows that for the higher impact energy its curve differs essentially in comparison to those obtained for two lowest impact energy levels considered. This demonstrates that the AM60 tested specimen can stop the projectile when energy takes $260 \mathrm{~J}$.

\subsection{Fractography}

Fracture zones after test conducted at the impact energy of $170 \mathrm{~J}$ are illustrated in Fig. 11. The specimen region for the projectile action was manifested by regular hole surrounded by significant plastic 


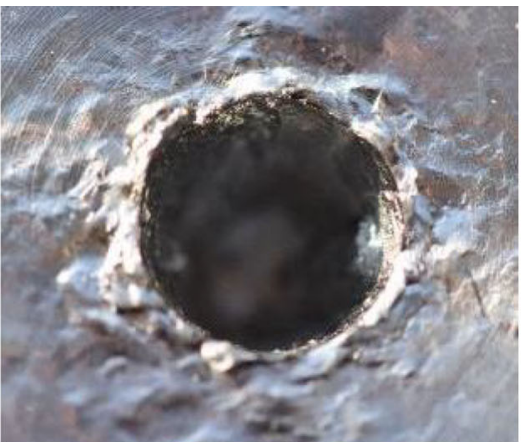

(a)

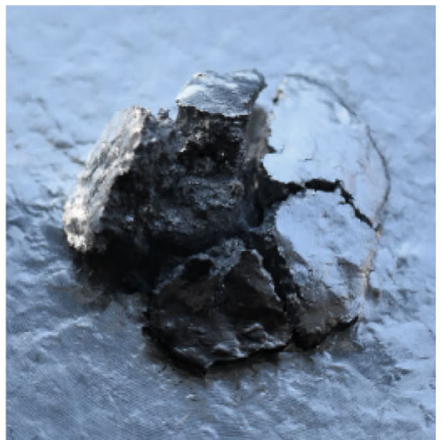

(b)

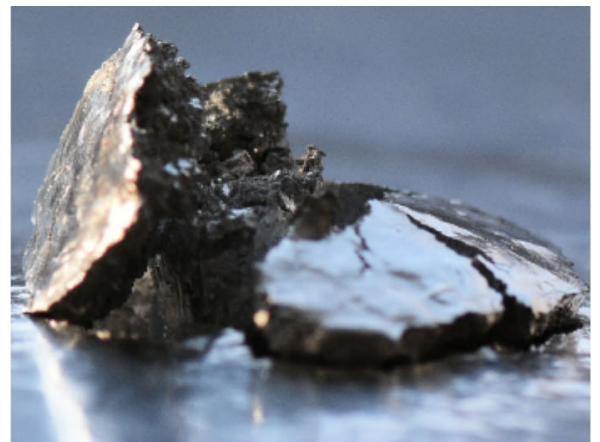

(c)

Fig. 11 Fracture zone of the AM60 magnesium alloy after impact test conducted at energy of $170 \mathrm{~J}: \mathbf{a}$ the projectile action side; $\mathbf{b}, \mathbf{c}$ the back side of the specimen

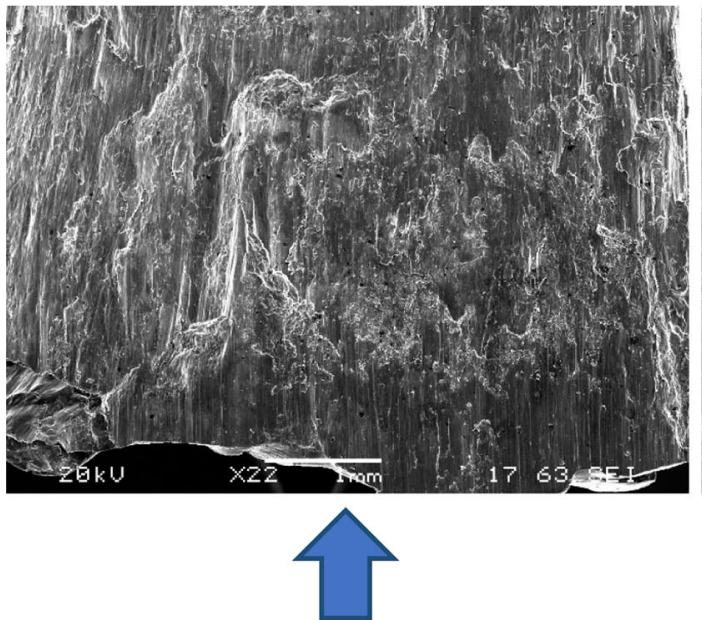

(a)

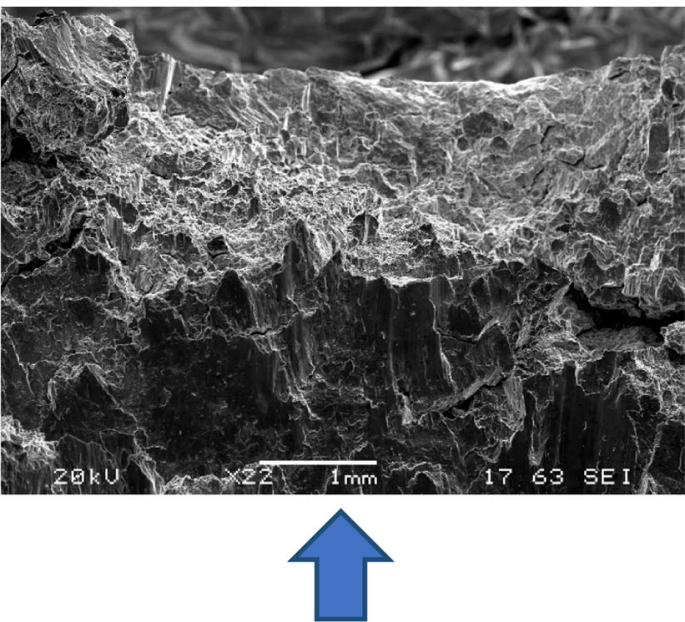

(b)

Fig. 12 Fracture zone of the AM 60 magnesium alloy after impact test conducted at energy of $170 \mathrm{~J}: \mathbf{a}, \mathbf{b}$ the front and back sides of the projectile action, the arrows represent direction of the projectile action

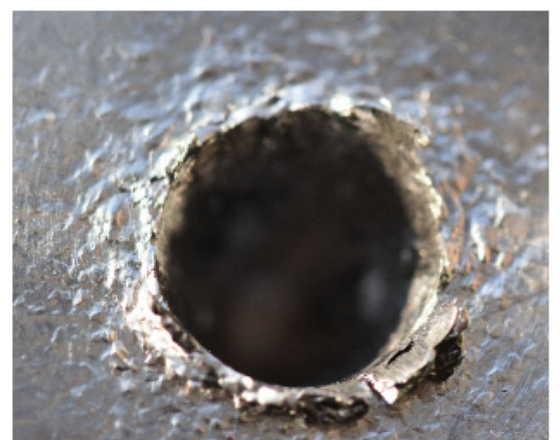

(a)

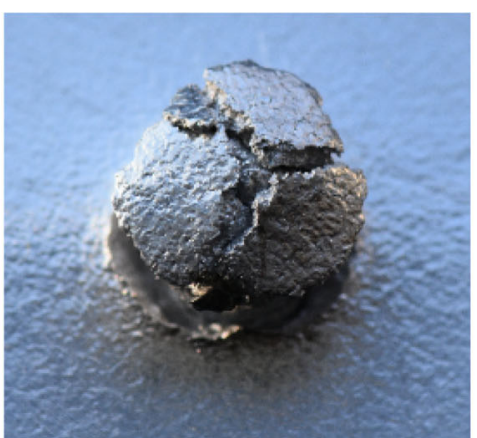

(b)

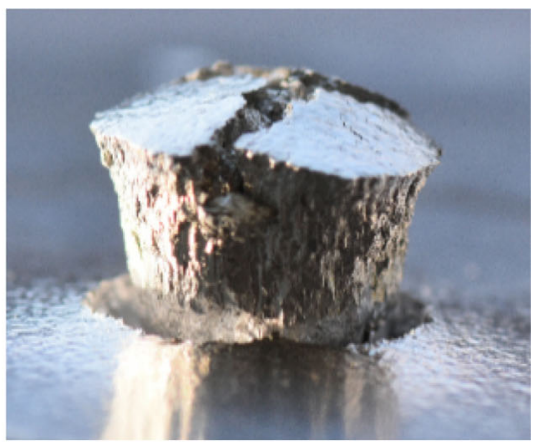

(c)

Fig. 13 Fracture zone of the AM60 magnesium alloy after impact test conducted at impact energy of $260 \mathrm{~J}$ : a projectile action side; $\mathbf{b}$, c back side of the specimen 

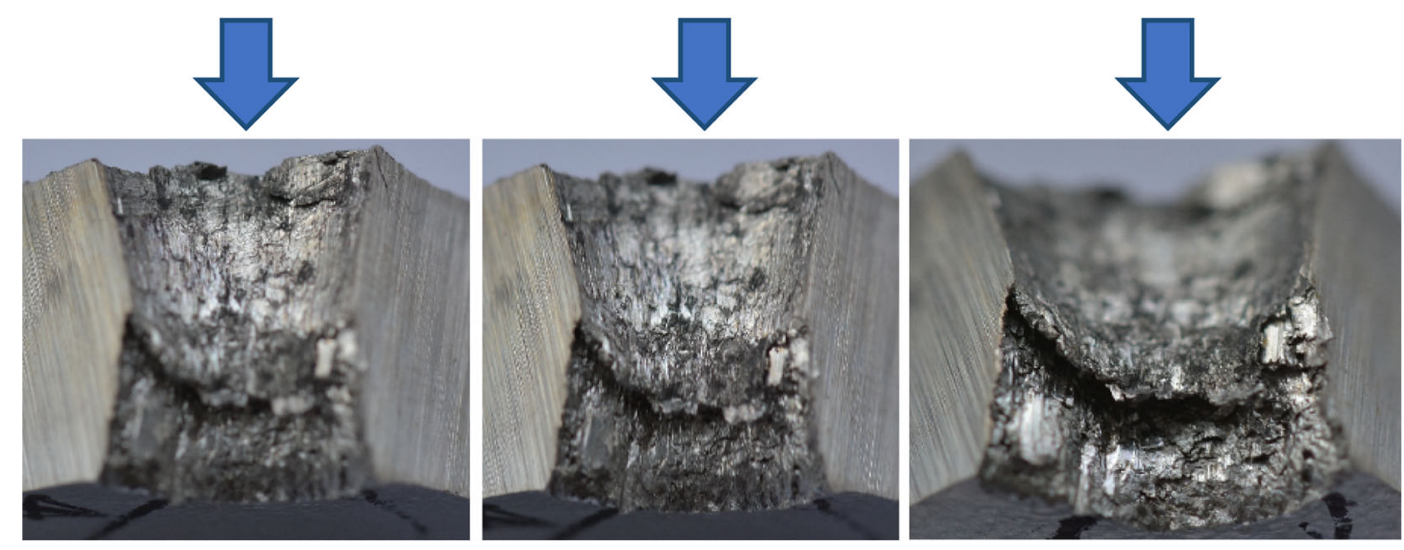

Fig. 14 Fracture zone of the AM 60 magnesium alloy after impact test conducted at energy of $260 \mathrm{~J}$; the arrows represent direction of the projectile action

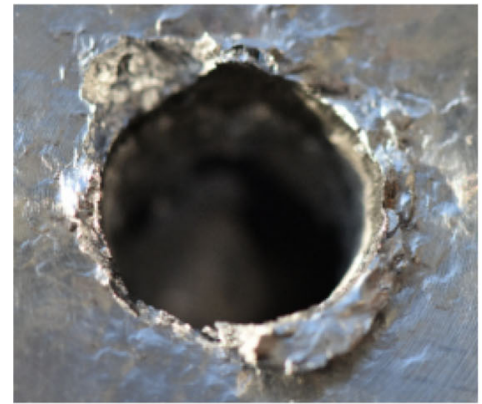

(a)

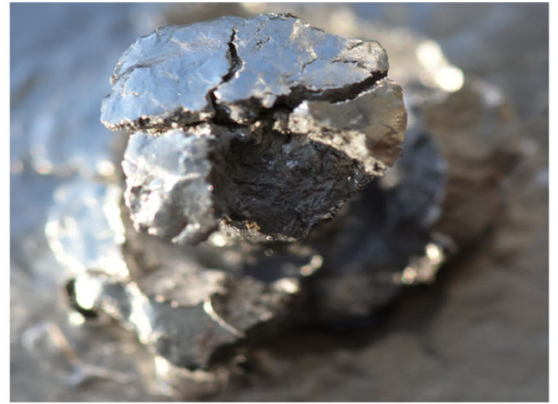

(b)

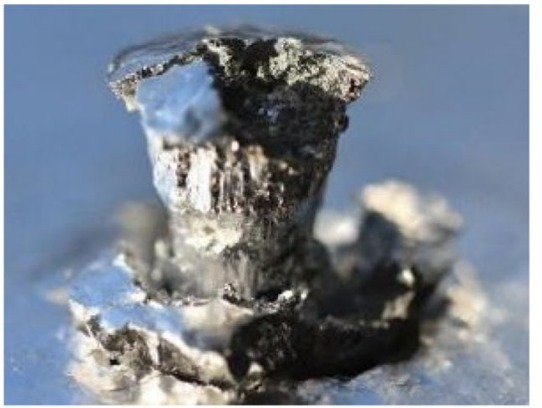

(c)

Fig. 15 Fracture zone of the AM60 magnesium alloy after impact test conducted at energy of $540 \mathrm{~J}$

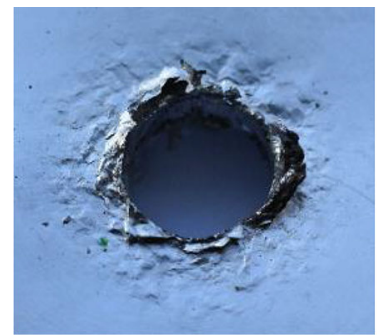

(a)

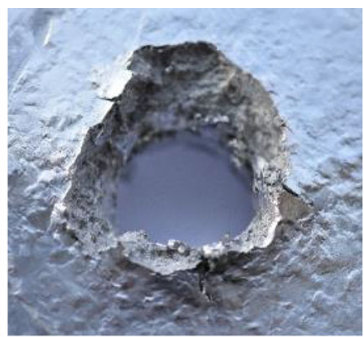

(b)
Fig. 16 Fracture zone of the AM60 magnesium alloy after impact test conducted at energy of $690 \mathrm{~J}$ deformation zone, Fig. 11a. On the opposite side of the impacted specimen a deformation mound represented by cracks arranged close to $120^{\circ}$ angle was visible in the form of brittle cracking of the alloy, Fig. 11b, c. SEM observation confirmed plastic deformation on a large zone of the projectile action, Fig. 12a, while in the case of a back-side area of the fracture section a brittle cracking was clearly seen, Fig. $12 b$.

For the impact energy of $260 \mathrm{~J}$ the $120^{\circ}$ angular brittle cracks arrangement was clearly visible, Fig. 13b. In addition to these features the damage 

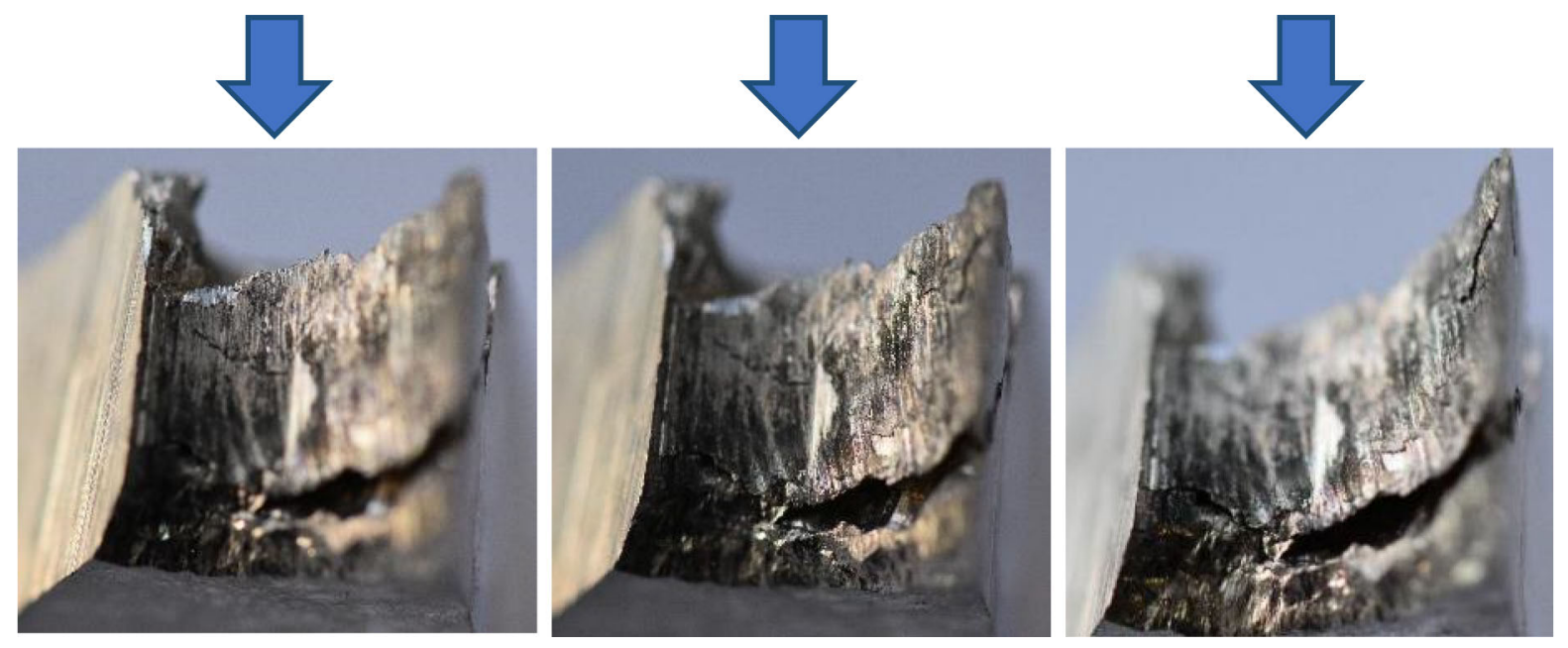

Fig. 17 Fracture zone of the AM 60 magnesium alloy after impact test conducted at energy of $540 \mathrm{~J}$; the arrows represent direction of the projectile action
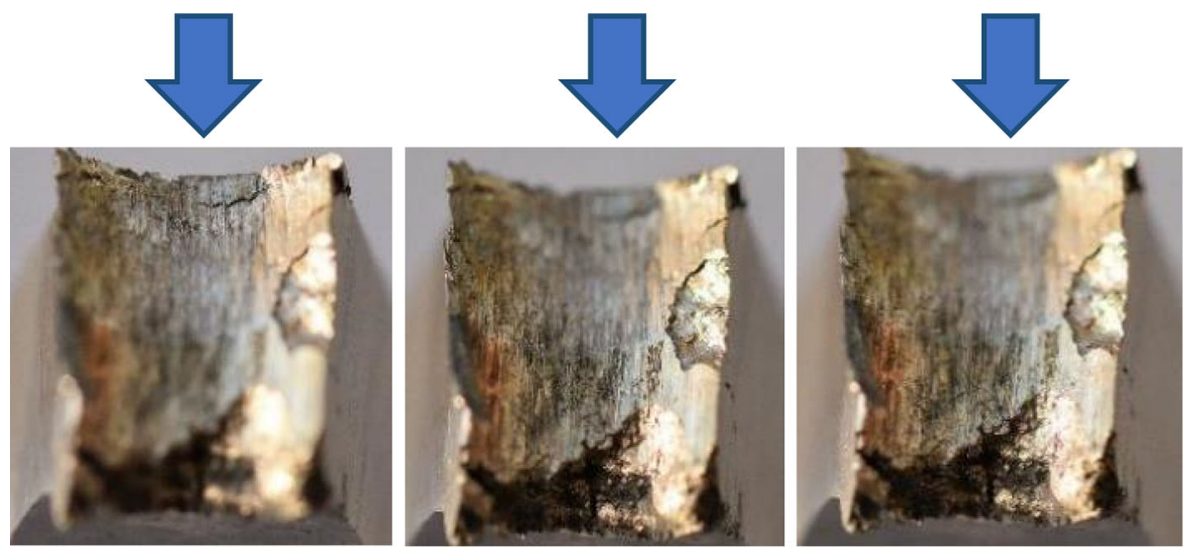

Fig. 18 Fracture zone of the AM 60 magnesium alloy after impact test conducted at energy of $690 \mathrm{~J}$; the arrows represent direction of the projectile action

zone was represented by a regular plug of the impacted material, Fig. 13c. Any defragmentation was not observed. In this case the fracture areas were characterised by two sections of various features. The first one is characterised by significant plastic deformation, the second one by brittle fracturing, Fig. 14. A transient border between both sections is also quite well illustrated. It occurred close to the middle section of specimen's thickness. 


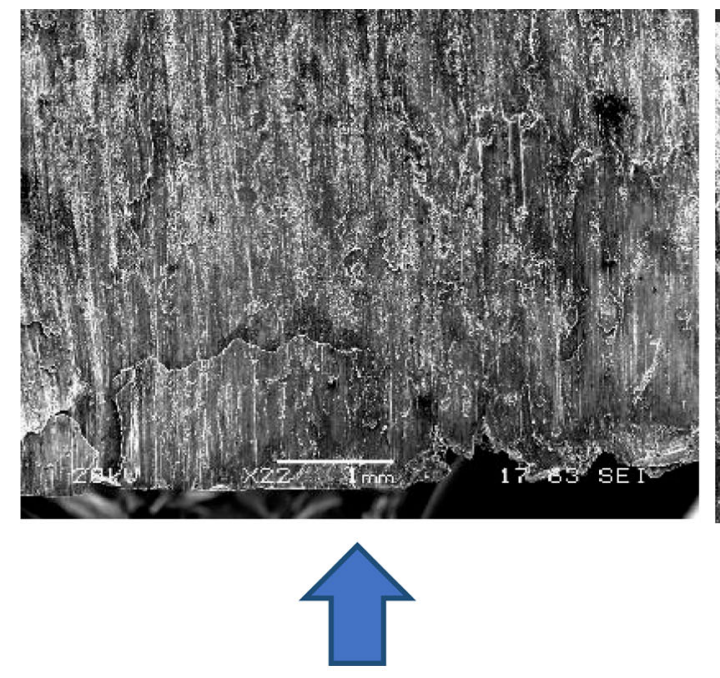

(a)

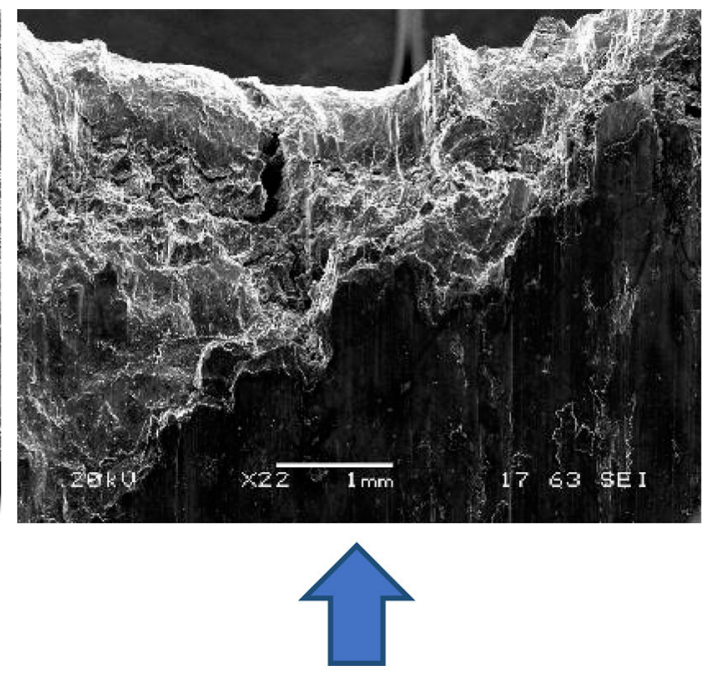

(b)

Fig. 19 Fracture zone of the AM 60 magnesium alloy after impact test conducted at energy of $690 \mathrm{~J}$; the arrows represent direction of the projectile action

Fracture zone of the projectile action at energy of $540 \mathrm{~J}$ shows wide regions of plastic deformation, Fig. 15. Three major cracks arranged on the opposite side of the specimen were also evidenced, showing brittle fracturing (Fig. 15b). In the case of experiments performed at $690 \mathrm{~J}$ important differences of material behaviour were noticed on the opposite side to that of the projectile action, Fig. 16b. In this case the hole was an effect of the impact energy.

A fracture zone on the specimen cross-section tested at the impact energy of $540 \mathrm{~J}$ presented plastic and brittle character of the material degradation for respectively nearly $3 / 4$ and $1 / 4$ of the specimen's thickness, Fig. 17. It has to be mentioned that in comparison to the results obtained for the alloy tested at lower energy, the major damage was moved to the specimen's back side. In the case of the highest impact energy the plastic zone was dominant reflecting movement of the projectile through the entire specimen's thickness, Fig. 18.

The images from SEM investigations illustrated plastic deformation bands (Fig. 19), the numbers of which increased with the increase of impact energy, Fig. 12a. The last section of the fracture zone was smaller than $1 \mathrm{~mm}$ showing brittle cracking, Fig. 19b.

\subsection{Microstructural observations of the magnesium alloy}

Observations of cracks after impact tests were carried out using SEM, Fig. 20. It enabled identification of cracks that appeared not only on the impact side, but also in the entire volume of the AM60 specimen tested. A number of cracks increased with increasing level of impact energy. 


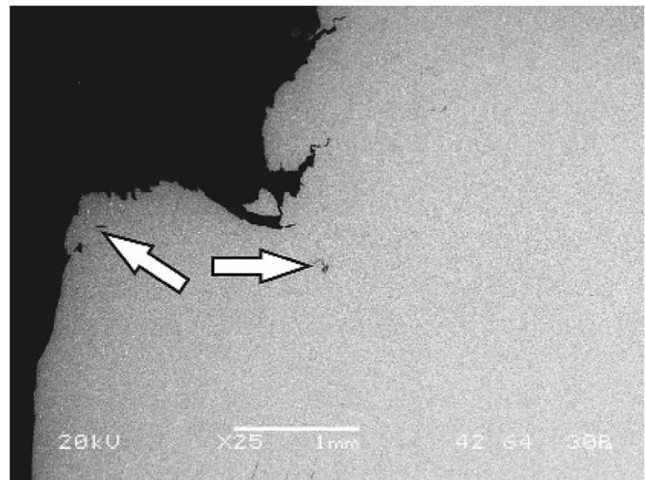

(a)

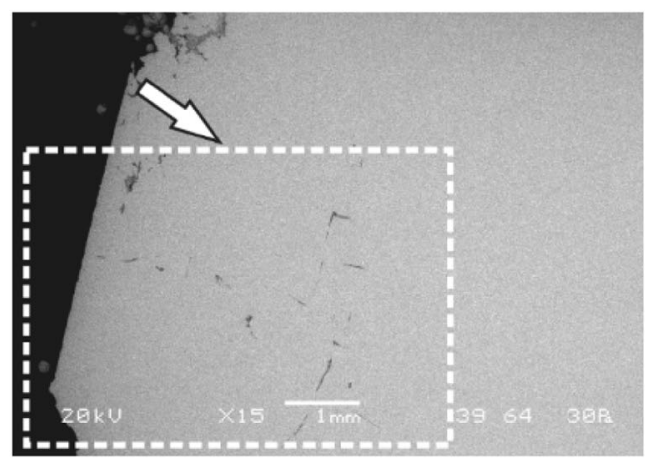

(c)

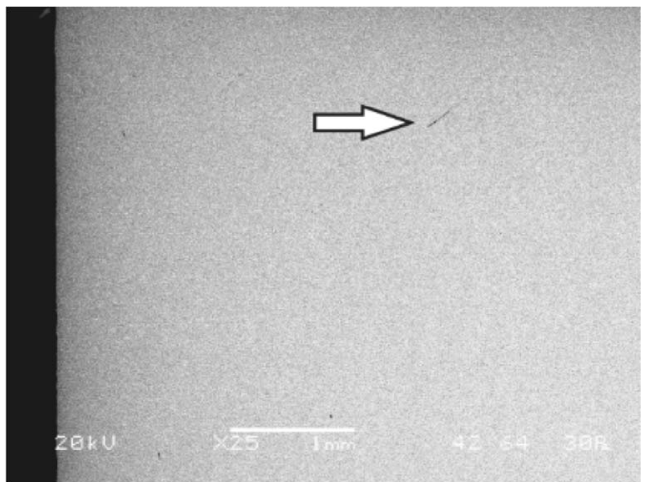

(b)

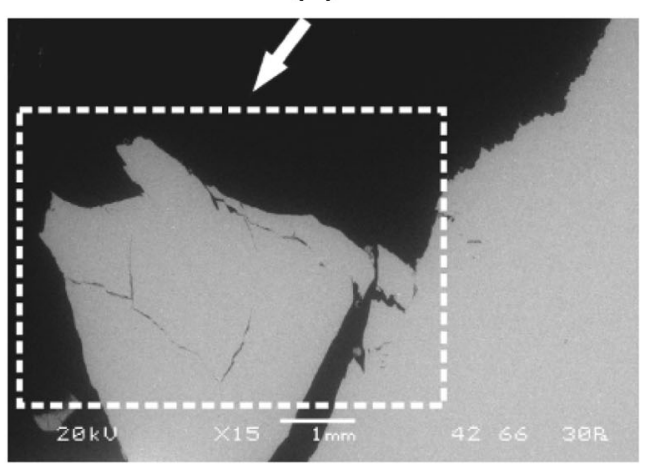

(d)

Fig. 20 The impact projectile zones obtained for the impact energy of a $170 \mathrm{~J}, \mathbf{b} 260 \mathrm{~J}, \mathbf{c} 540 \mathrm{~J}, \mathbf{d} 690 \mathrm{~J}$

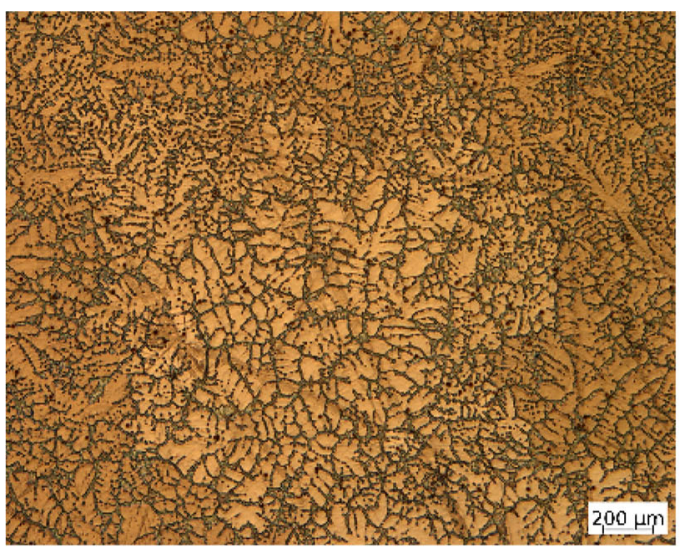

(a)

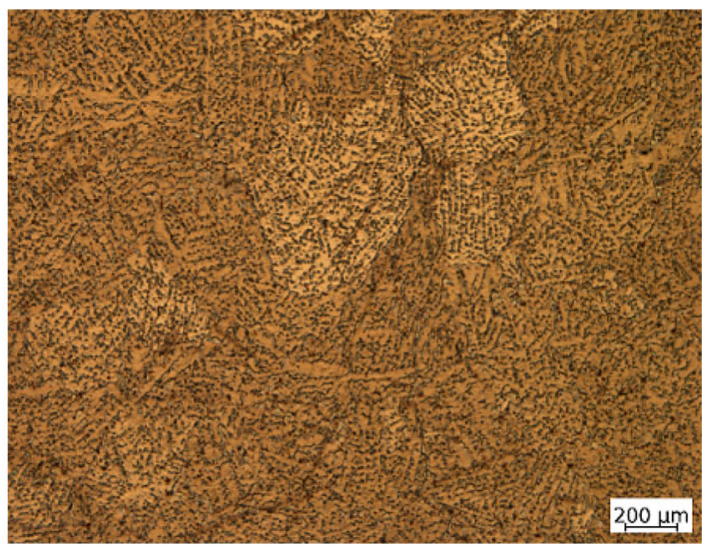

(b)

Fig. 21 Microstructures of the AM60 alloy in the as-received state with respect to the morphology of eutectic $\mathrm{Mg}_{17} \mathrm{Al}_{12}$ in $\alpha-\mathrm{Mg}$ matrix of the specimens tested under impact energy equal to: a $170 \mathrm{~J}$; b $260 \mathrm{~J}$; magnification $\times 25$ 


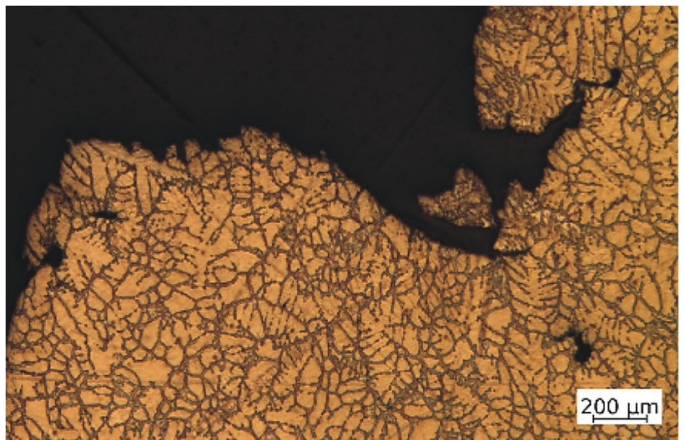

(a)

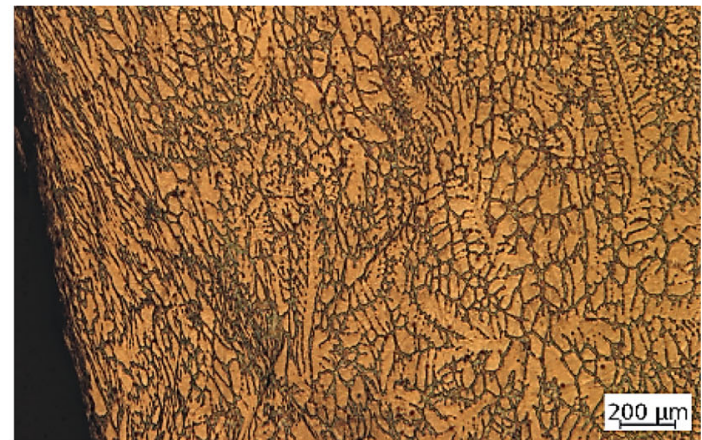

(b)

Fig. 22 The AM60 microstructure degradation at impact energy of $170 \mathrm{~J}$ : a cracks, b plastic deformation; magnification $\times 25$

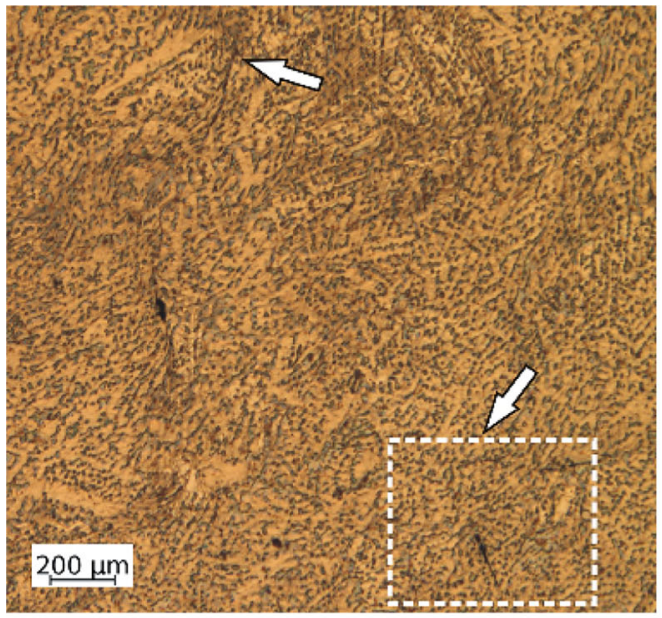

(a)

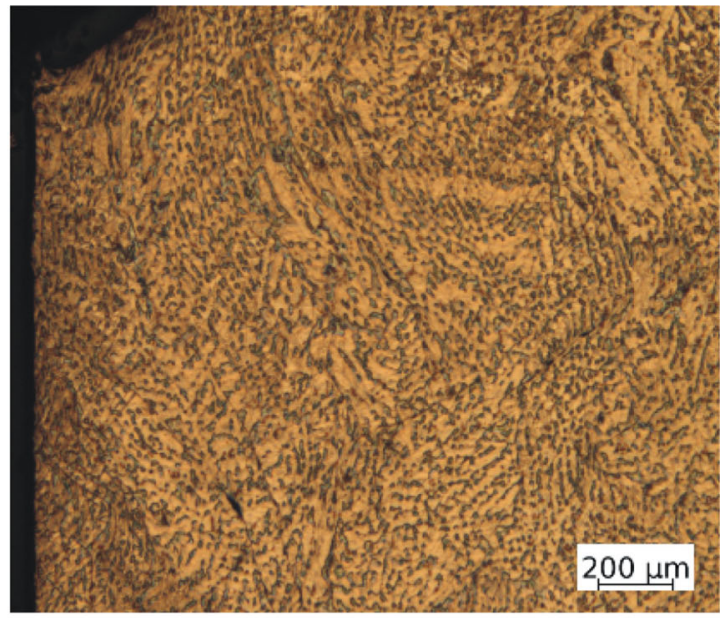

(b)

Fig. 23 The AM60 microstructure degradation at impact energy of $260 \mathrm{~J}$ : a cracks, b plastic deformation; magnification $\times 25$

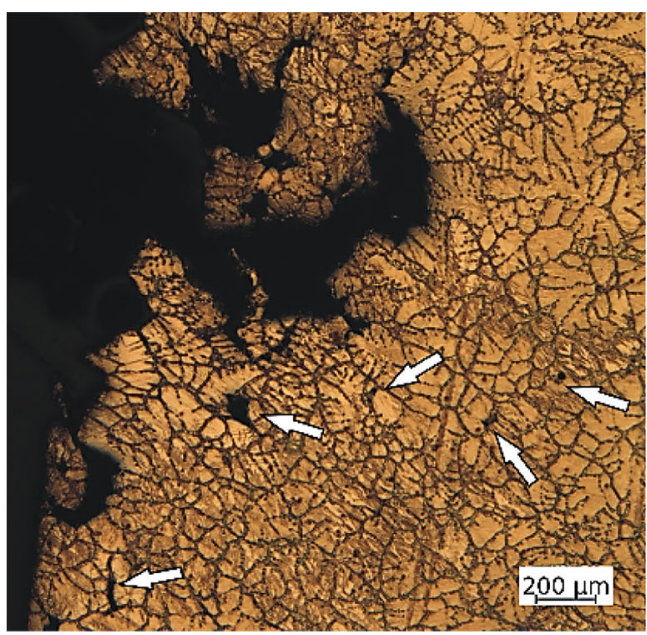

(a)

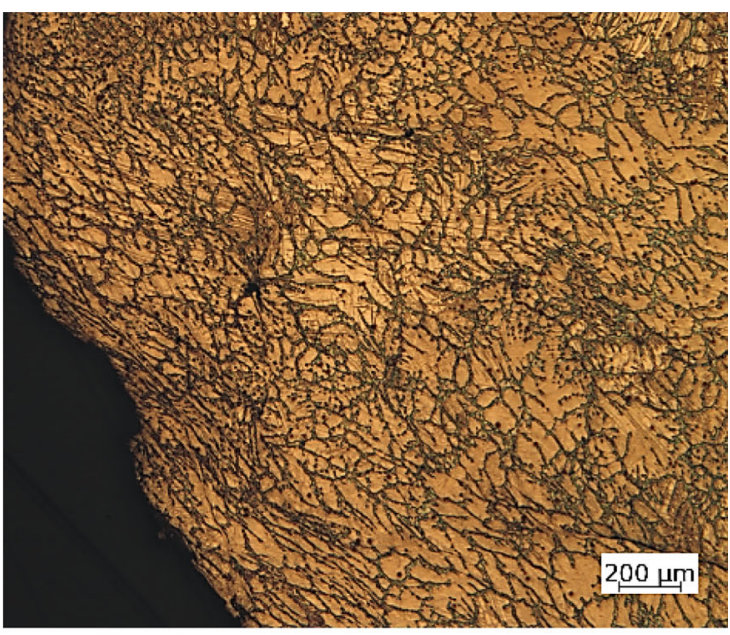

(b)

Fig. 24 The AM60 microstructure degradation at impact energy of $540 \mathrm{~J}$ : a cracks, b plastic deformation; magnification $\times 25$ 


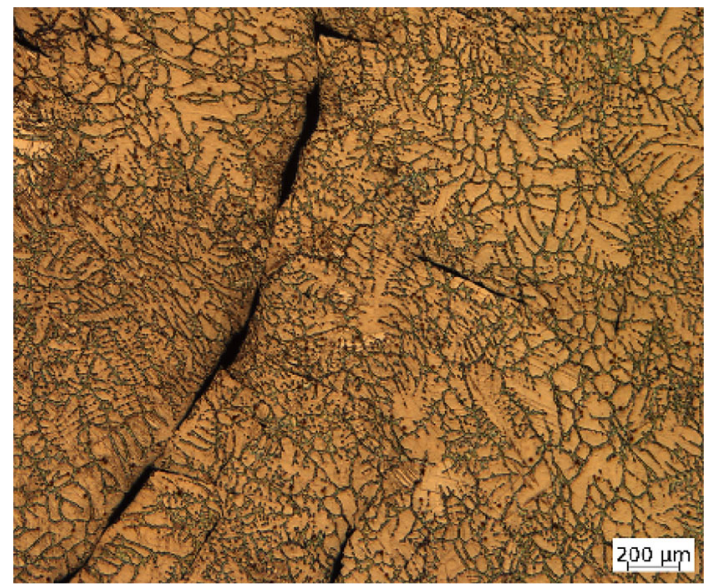

Fig. 25 Cracks arrangement in the specimen tested at impact energy of $540 \mathrm{~J}$; magnification $\times 25$

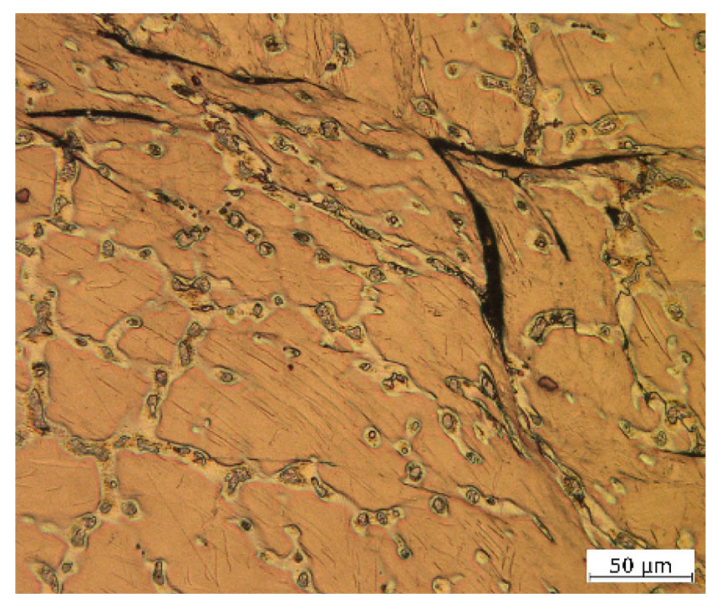

Fig. 26 Changes of direction of cracks propagation and progressive plastic deformation, impact energy of $540 \mathrm{~J}$; magnification $\times 200$
Etched specimens' observation with the use of the light microscope (LM) exhibited that the lower fraction of cracks on the surface of specimen subjected to impact energy of $260 \mathrm{~J}$ is related to finer size and more globular shape of eutectic precipitations $\mathrm{Mg}_{17-}$ $\mathrm{Al}_{12}$ in $\alpha$-Mg matrix (Fig. 21).

Cracks appearing on the impact surface were strongly related to the projectile action, Figs. 22a, $23,24 \mathrm{a}$ and $27 \mathrm{~b}$. Along with increase of distance from this zone, the plastic deformation of the material matrix becomes more significant, Figs. $22 \mathrm{~b}$ and $24 \mathrm{~b}$. The impact energy of $540 \mathrm{~J}$ led to variations in damage mechanisms, Figs. 25 and 26. In this case a significant increase of fraction cracks quantity and their coalescence in the specimen volume were observed, Figs. 25 and 26. These cracks occurred in different directions, including perpendicularly to the projectile action, Fig. 25.

Defragmentation of the impact zone was evidenced at energy of $690 \mathrm{~J}$ (Fig. 27a). Moreover, two various traces of major cracks can be clearly observed, i.e. along a brittle precipitations of the $\mathrm{Mg}_{17} \mathrm{Al}_{12}$ (Fig. 28a) and slip bands (Fig. 28b). 


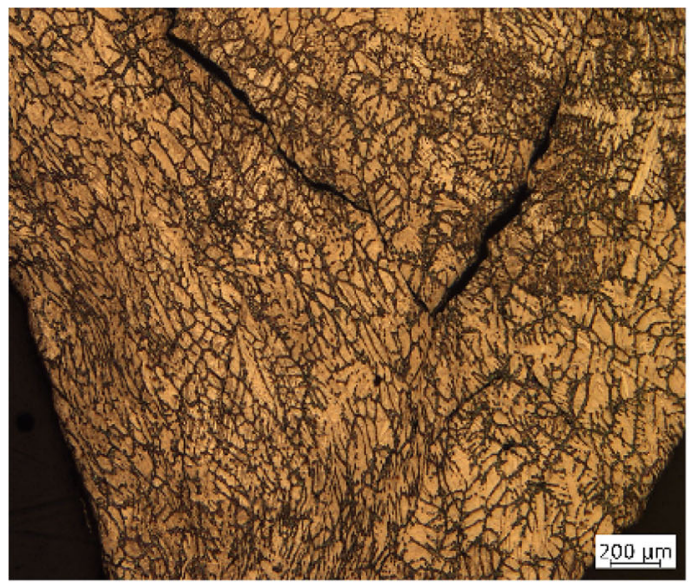

(a)

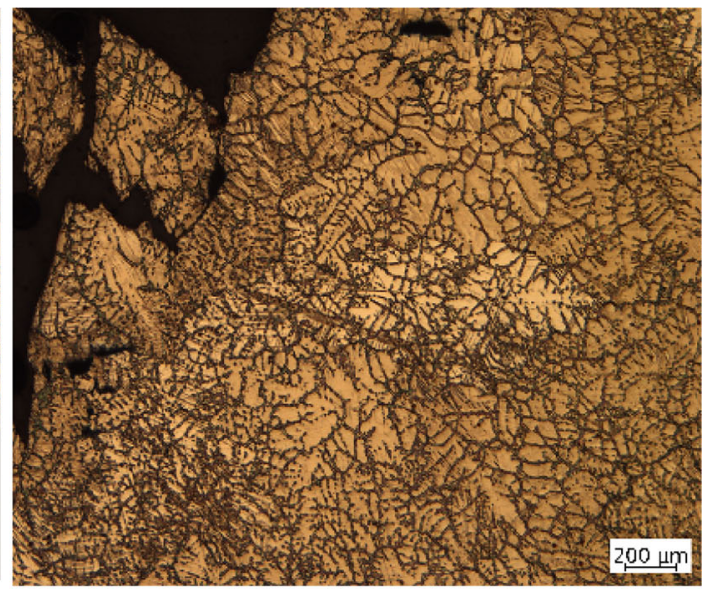

(b)

Fig. 27 The AM60 microstructure degradation evidenced for the impact zone at energy of $690 \mathrm{~J}$ : a cracks and plastic deformation region inside defragmented material, $\mathbf{b}$ material defragmentation on the impact zone; magnification $\times 25$

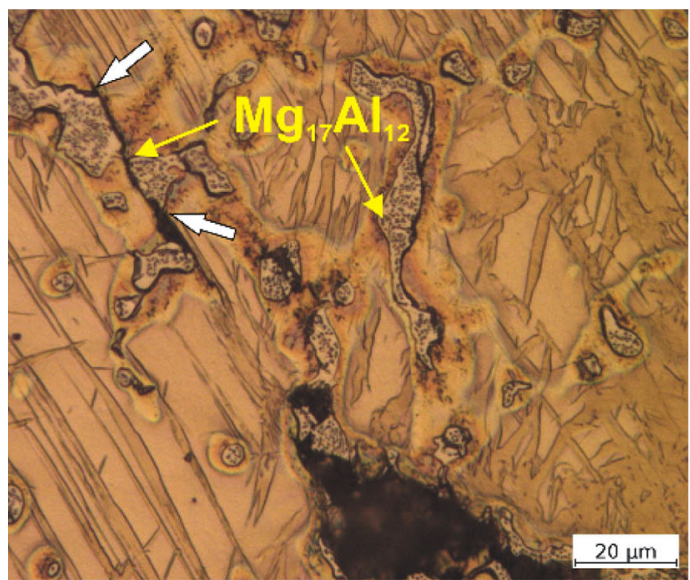

(a)

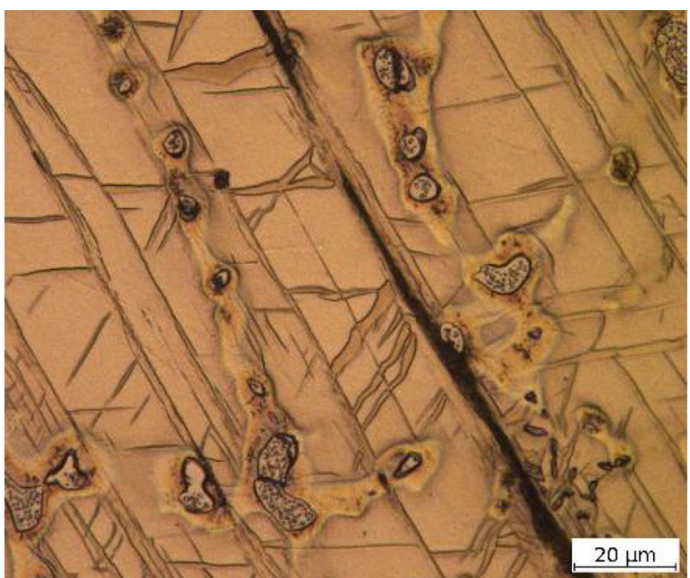

(b)

Fig. 28 Variants of cracks taking place along: a eutectic $\mathrm{Mg}_{17} \mathrm{Al}_{12}$ near the fracture surface, b slip band, $(\mathrm{E}=690 \mathrm{~J})$; magnification $\times 500$

\section{Conclusions}

Mechanical behaviour of the AM60 magnesium alloy under impact loading was strongly related to the energy applied. The material holds the projectile at the energy below $500 \mathrm{~J}$. For impact energy within range of 260-540 J the fracture zones of the material tested were represented by a few cracks and plug-shaped deformation. A fracture zone was represented by changes in the alloy fracturing from plastic to brittle. The number of plastic bands and their area increased with the increase of impact energy.
The AM60 microstructure degradation was generally expressed by a small number of cracks and their coalescence with energy increase. A number of cracks became more significant with increase of impact energy value. For the highest impact energy applied cracks appeared in precipitation and slip bands.

Variations of accumulated energy, projectile velocity and its displacement may be used for validation of the AM60 behaviour in numerical modelling and calibration of constitutive equations describing dynamic phenomena in experiments carried out. It can be used in theoretical approaches for prediction of 
the tested material behaviour. This issue is our next step in future investigations.

Acknowledgements The paper was prepared in the framework of the Project No. DOBR-BIO4/024/13237/2013 founded by the National Centre for Research and Development.

Open Access This article is distributed under the terms of the Creative Commons Attribution 4.0 International License (http:// creativecommons.org/licenses/by/4.0/), which permits unrestricted use, distribution, and reproduction in any medium, provided you give appropriate credit to the original author(s) and the source, provide a link to the Creative Commons license, and indicate if changes were made.

\section{References}

Ambrosini J.F.: Simulation of ballistic impacts in steel plates. Faculté Polytechnique, June 51 pp. (2015)

Borvik, T., Langseth, M., Hoperstad, O.S., Malo, K.A.: Perforation of $12 \mathrm{~mm}$ thick steel plates by $20 \mathrm{~mm}$ diameter projectiles with flat, hemispherical and conical noses part I: experimental study. Int. J. Impact Eng. 27(1), 19-35 (2002a)

Borvik, T., Langseth, M., Hoperstad, O.S., Malo, K.A.: Perforation of $12 \mathrm{~mm}$ thick steel plates by $20 \mathrm{~mm}$ diameter projectiles with flat, hemispherical and conical noses part II: numerical study. Int. J. Impact Eng. 27(1), 37-64 (2002b)

Borvik, T., Hoperstad, O.S., Langseth, M., Malo, K.A.: Effect of target thickness in blunt projectile penetration of Weldox 460 E steel plates. Int. J. Impact Eng. 28, 413-464 (2003)

Cheshire, E., Rossi, M., Atkins, T.: Perforation of sheets by pyramidal weapons such as arrowheads. Int. J. Impact Eng. 35(6), 457-470 (2008)

DiCecco S., Hu H., Altenhof W.: Impact and energy dissipation characteristics of squeeze and die cast magnesium alloy AM60. In: Mathaudhu, S.N., Sillekens, W.H., Neelameggham, N.R., Hort, N. (eds.) Magnesium Technology 2012, TMS 2012, pp. 165-168. The Minerals, Metals \& Materials Society (2012)

Dey, S., Børvik, T., Teng, X., Wierzbicki, T., Hopperstad, O.S.: On the ballistic resistance of double-layered steel plates: an experimental and numerical investigation. Int. J. Solids Struct. 44, 6701-6723 (2007)

Engineered casting solutions, magnesium alloys. The American Foundry Society Technical Department, Schaumburg, IL, USA, 3 pp

Godzimirski, J., Janiszewski, J., Rośkowicz, M., Surma, Z.: Ballistic resistance tests of multi-layer protective panels. Maint. Reliab. 17(3), 416-421 (2015)
Gupta, N.K., Iqbal, M.A., Sekhon, G.S.: Experimental and numerical studies on the behaviour of thin aluminium plates subjected to impact by blunt- and hemisphericalnosed projectiles. Int. J. Impact Eng. 32(12), 1921-1944 (2006)

Gupta, N.K., Iqbal, M.A., Sekhon, G.S.: Effect of projectile nose shape, impact velocity and target thickness on deformation behaviour of aluminium plates. Int. J. Solids Struct. 44(10), 3411-3439 (2007)

Hebben R.: The material and its properties. Magnesium Diecasting, STIHL folder, 4 pp (2010). https://magnesium. stihl.com/p/media/download/d4/material_and_properties. pdf

Moćko, W., Kowalewski, Z.L.: Perforation test as an accuracy evaluation tool for a constitutive model of austenitic steel. Arch. Metall. Mater. 58(4), 1105-1110 (2013)

Musfirah, A.H., Jaharah, A.G.: Magnesium and aluminum alloys in automotive industry. J. Appl. Sci. Res. 8(9), 4865-4875 (2011)

Piekutowski, A.J.: Holes produced in thin aluminium sheets by the hypervelocity impact of aluminium spheres. Int. J. Impact Eng. 23, 711-722 (1999)

Rusinek, A., Rodríguez-Martínez, J.A., Zaera, R., Klepaczko, J.R., Arias, A., Sauvelet, C.: Experimental and numerical study on the perforation process of mild steel sheets subjected to perpendicular impact by hemispherical projectiles. Int. J. Impact Eng. 36, 565-587 (2009)

Shen, W.Q., Rieve, R.O., Baharun, B.: A study of the failure of circular plates struck by masses, part 1: experimental results. Int. J. Impact Eng. 27, 399-412 (2002)

Tomac, N., Tonnessen, K., Mikac, T.: Study of influence of aluminium content onmachinability of magnesium alloys. Strojarstvo 50(6), 363-367 (2008)

Wierzbicki, T.: Petalling of plates under explosive and impact loading. Int. J. Impact Eng. 22, 935-954 (1999)

www.instron.com

Yan, C., Bai, R.X., Gu, Y.T., Ma, W.J.: Investigation on mechanical behaviour of AM60 magnesium alloys. J. Achiev. Mater. Manuf. Eng. 31(2), 398-401 (2008)

Zhang, X., Fang, L., Xiong, B., Hu, H.: Microstructure and tensile properties of $\mathrm{Mg}(\mathrm{AM} 60) / \mathrm{Al}_{2} \mathrm{O}_{3}$ metal matrix composites with varying volume fractions of fiber Reinforcement. J. Mater. Eng. Perform. 24(12), 4601-4611 (2015)

Zhong, W.Z., Mbarek, I.A., Rusinek, A., Bernier, R., Jankowiak, T., Sutter, G.: Development of an experimental setup for dynamic force measurements during impact and perforation, coupling to numerical simulations. Int. J. Impact Eng. 91, 102-115 (2016)

Publisher's Note Springer Nature remains neutral with regard to jurisdictional claims in published maps and institutional affiliations. 